SUR Y TIEMPO. REVISTA DE HISTORIA DE AMÉRICA. №2, 2020.

\title{
Cultura en Transición, música en Continuación (1989-2005) ${ }^{1}$
}

Culture in Transition, music in Continuation (1989-2005)

César Albornoz C.

Pontificia Universidad Católica de Chile

cealborn@uc.cl

\section{Resumen}

Desde el fin de la dictadura de Pinochet, el año 1989 se inició en Chile un período de ajuste con la implementación de una democracia en el marco de la constitución de 1980, y de un modelo económico sostenido en el liberalismo económico en su implementación más radical. En ese marco, la cultura se desarrolló conforme a una estructura donde la tecnología e incipiente globalización, entre otros, fueron factores relevantes que definieron experiencias artísticas, dentro de las cuales la música popular fue significativa. Su manifestación sonora y experiencia social, bien representan simbólicamente las características más importantes del período comprendido entre 1989 y 2005, época en que géneros como la canción de autor, la música afro o la música electrónica marcaron presencia. Sin embargo, hubo uno que mejor da cuenta de esa historia, concentrando en sus letras, formas de interpretación e impacto social, las características más importantes de aquel tiempo: el rap.

Palabras clave: Música; cultura; Chile; Transición; rap; globalización.

\section{Abstract}

Since the end of the Pinochet dictatorship in 1989, a period of adjustment began in Chile with the implementation of a democracy within the framework of the 1980 constitution and an economic model sustained in the most radical liberalism. In this context, culture developed according to a structure where technology and incipient globalization, among others, were relevant factors where certain artistic experiences such as popular music were very important. Its sound manifestation and social

1 La investigación desarrollada para este artículo se vincula con experiencia de cátedra y el Proyecto “El Nuevo Rock Chileno y su rol en los años de la post Dictadura chilena (1990-2000)". Fondo de la Música / Investigación y Registro de la Música Nacional / Investigación, Publicación y Difusión. Folio 531924, año 2020. 
experience symbolically represent very well the characteristics of the period between 1989 and 2005; a time when genres like composers, afro music or electronic music were very present. However, there was a genre that best explains that story, concentrating on its lyrics, forms of interpretation and social impact, the most important characteristics of the time: rap music.

Keywords: Music; culture; Chile; Transition; rap; globalization.

\section{Introducción}

Si para la historia de Chile suscribiéramos la tesis de Eric Hobsbawm acerca de la existencia de un siglo XX corto, concluyente en 1991 con el fin de la URSS (Hobsbawm, 1998: 20), el nuestro sería el año 1989, ocasión en que Patricio Aylwin gana las primeras elecciones libres realizadas en el país desde aquella parlamentaria de marzo de 1973, asumiendo como presidente de la república, acabando con la dictadura de Pinochet e iniciando un período que sería conocido como de Transición. Transición ¿hacia dónde? 0 en otras palabras, ¿en qué momento termina? Claro, suponiendo que se ha acabado.

Determinemos un año simbólico, desde lo político, para definir el fin de ésta. "Ahora podemos decir que la transición en Chile ha concluido. Ahora tenemos un cuerpo constitucional que está acorde con la tradición histórica de Chile y lo más importante, un cuerpo constitucional que fue aceptado por la unanimidad en el Congreso Nacional" 2 , afirmó el entonces presidente socialista y militante del Partido Por la Democracia (PPD) Ricardo Lagos. Suscribamos esta aseveración: el año 2005 se acabó la transición, luego de 16 años. ¿Cómo la cultura dio cuenta de ello? ¿Hubo una cultura de transición? Ya que definimos un rango temporal, la pregunta es: ¿Podemos identificar o reconocer algunas características específicas que tuvieron las expresiones artístico culturales para este tiempo, que permitan reconocerlas como un cuerpo coherente? Dentro de todo esto, ¿podemos decir que hay una música popular en transición?

Para responder estas preguntas nos sostendremos en dos preceptos. Primero, entenderemos por cultura la acepción derivada del giro antropológico de las ciencias sociales que, a la luz de autores como Clifford Geertz (1973: 88) o Peter Burke (2010: 66) -desde la antropología y la historiografía, sucesivamente- reconocen en ésta un conjunto de actitudes, mentalidades y valores que bien se depositan en

2 Cooperativa.cl. Jueves 14 de julio de 2005. Disponible en web: https://www.cooperativa.cl/noticias/pais/politica/reformas-constitucionales/presidente-lagosreformas-constitucionales-marcan-el-fin-de-la-transicion/2005-07-14/100948.html [Consulta: 17 de abril de 2020] 
artefactos que los contienen y representan, y que simbólicamente dan cuenta de sus correspondientes sociedades con sus tiempos y espacios. Durante el período en estudio se publicó una de las obras más robustas en cuanto a análisis histórico cultural de la historia contemporánea de Chile desde la música: Juan Pablo González y Claudio Rolle editaron Historia social de la música popular en Chile 1890-1950. En éste definen cultura como "Sistema de significados, actitudes y valores compartidos, junto a las formas simbólicas a través de las cuales éstos se expresan y traducen, que nos es próxima y lejana a la vez. Se trata de expresiones que nacieron en épocas con sensibilidades distintas a las nuestras y que no buscaron documentar un determinado momento para los investigadores del futuro, sino más ben comunicar, seducir y emocionar" (González y Rolle, 2005: 18). Es esta también nuestra concepción de cultura.

Segundo, cuando nos enfrentamos al desafío de considerar la cultura como un objeto de estudio para un espacio y tiempo determinado, no podemos desde la historia desatender que sus productos, las expresiones culturales y artísticas, no son sólo un tema de estudio, sino también un vestigio sobre el cual se sostiene nuestra metodología. Se complejiza así el objeto al transformarse también en sujeto. La música es un tema a estudiar, pero también una expresión histórica que representa simbólicamente actitudes, mentalidades y valores. Por lo mismo, se deben atender tres dimensiones de toda expresión cultural y de la música en particular: texto, soporte y contexto. Ello, sobre la base de la reflexión de uno de los más importantes historiadores preocupados de la cultura, Roger Chartier, quien al reflexionar sobre su tema de especialización -a saber, la historia del libro-afirma:

Cualquier reflexión metodológica se arraiga, en efecto, en una práctica histórica en particular, en un espacio de trabajo específico. El mío se organiza alrededor de tres polos, generalmente desunidos por las tradiciones académicas: por un lado, el estudio crítico de los textos [...]; por otro, la historia de los libros y de todos los objetos que llevan la comunicación de lo escrito; por último, el análisis de las prácticas que, diversamente, se apoderan de los bienes simbólicos, produciendo así usos y consideraciones diferenciadas (Chartier, 1992: 50)

Sobre esta base podemos enfrentarnos a una posible cultura y música en transición, conociéndola como fenómeno, pero sobre todo reconociéndola como representación simbólica de dimensión temporal de la sociedad chilena para el período 1989-2005. 


\section{Contexto}

"Transición" es un concepto político y, por lo tanto, amerita una aproximación a la historia de Chile desde esa perspectiva.

Como decíamos, el triunfo electoral con mayoría absoluta de Patricio Aylwin sobre sus opositores, el ex Ministro de Hacienda de los últimos años de la dictadura Hernán Büchi, y el empresario Francisco Javier Errázuriz, implicó la aparente recuperación de la democracia, encabezada por la presidencia del líder democratacristiano de la Concertación de Partidos por la Democracia. Su opción por una oposición moderada a la dictadura -muy distante de una mucho más intransigente con la que, junto a Sergio Onofre Jarpa, del Partido Nacional, lideró la oposición al gobierno de la Unidad Popular-, se plasmó en un gobierno conciliador, bajo el cual la consigna "democracia de los acuerdos" fue predominante. Mas, la herencia política del gobierno de Pinochet era evidente y así lo demostrarían dos procesos.

Primero, la generalizada impunidad frente a la violación sistemática de los derechos humanos, llevada a cabo por agentes del Estado bajo el mando del gobierno pinochetista. La opción fue investigar, mas no hacer justicia, a no ser que fuera "en la medida de lo posible" 3 . Para ello se creó por Decreto Supremo no 355 del 25 de abril de 1990, la Comisión Nacional de Verdad y Reconciliación (no justicia), la que explicitó como sus objetivos "establecer un cuadro lo más completo posible sobre los graves hechos de violación a los derechos humanos, sus antecedentes y circunstancias; reunir información que permitiera individualizar a las víctimas y establecer su suerte y paradero; recomendar las medidas de reparación o reivindicación que estimara de justicia; y recomendar las medidas legales y administrativas que a su juicio debieran adoptarse para impedir o prevenir la comisión de nuevos atropellos graves a los derechos humanos (Chile. Corporación Nacional de Reparación y Reconciliación y Comisión Nacional de Verdad y Reconciliación, 1991: 1). Privilegiando el esclarecimiento de los hechos por sobre las responsabilidades penales, los primeros años de una supuesta transición se conformaban con una estabilidad política antes que un saneamiento moral. "Debemos abordar este delicado asunto conciliando la virtud de la justicia, con la virtud de la prudencia y concretadas las responsabilidades que corresponda, llegará la hora del perdón", exclamaba el presidente en su primer discurso en el Estadio

\footnotetext{
${ }^{3}$ La frase completa fue: "La conciencia moral de Chile exige que se esclarezca la verdad y que se haga justicia, en la medida de lo posible". El Mercurio, 13 de junio de 1990. Disponible en web: https://www.emol.com/noticias/Nacional/2016/04/19/798750/Las-frases-que-dejo-Patricio-Aylwinen-su-vida-politica.html [Consulta: 18 de abril de 2020]
} 
Nacional ${ }^{4}$. La continuidad de la dictadura se evidenciaba en amagos de impunidad de la democracia.

Los intentos por avanzar en investigaciones penales y juicios a los culpables -dentro de los cuales el procesamiento al director de la Dirección de Inteligencia Nacional DINA, Manuel Contreras, fue emblemático- fueron permanentemente inhibidos por amenazas solapadas o patentes de parte de las Fuerzas Armadas. El "ejercicio de enlace", así llamado por el Ejército, del 19 de diciembre de 1990, y el "boinazo", como se conoció coloquialmente a la salida a las calles de comandos del ejército en tenida de combate, del 28 de mayo de 1993, fueron dos evidencias de aquello. El Ejército, aún liderado por Pinochet, y el conglomerado político que lo respaldaba y amparaba desde la dictadura seguían siendo dominantes en la política nacional.

Un segundo punto fue la continuidad del modelo político-económico fundado por la dictadura. En este sentido afirma el historiador Manuel Gárate:

Las promesas del programa de gobierno concertacionista fueron readecuadas en la medida que las nuevas autoridades económicas no quisieron entrar en conflicto con la coalición de facto que existía entre empresarios, la derecha política, los militares y parte importante del poder judicial (Gárate, 2014: 373-374)

Las políticas ejercidas desde un Estado subsidiario, privilegiando la iniciativa privada como eje de la generación de empleos y, por ende, del crecimiento económico, generó una apariencia de bienestar social que se vociferaba con índices macroeconómicos auspiciosos. Efectivamente, el año 1995 se anunció que Chile había crecido en un 35\%, cifra récord para la época. Mas, las privatizaciones implicaban una ampliación de la distancia entre ricos y pobres, segmento que eufemísticamente era conocido ahora como "vulnerable".

Pues la fragilidad del modelo se alumbró con la crisis asiática de 1998. Los índices macroeconómicos bajaron a cifras similares a las de la crisis de los años ochenta, y la imagen de país desarrollado empezó a ser cuestionada o, al menos, tensionada. Destacados intelectuales como el sociólogo Tomás Moulian, el historiador Alfredo Jocelyn-Holt o el economista Marcel Claude publicaban provocadores libros al respecto (Moulian, 1997; Jocelyn-Holt, 1998; Claude, c1997).

En términos políticos, factores como el régimen binominal, la cifra repartidora y sobre todo la institución de los senadores designados, que implicaban la presencia en el congreso de la figura de Augusto Pinochet bajo la investidura de

\footnotetext{
4 Patricio Aylwin. Discurso en el Estadio Nacional del 12 de marzo de 1990. Archivo Presidencial. Disponible en web: https://www.gob.cl/noticias/el-discurso-con-que-patricio-aylwin-reinauguro-lademocracia-1/ [Consulta: 5 de julio de 2019]
} 
senador vitalicio, no podían ser más elocuentes de continuismo desde la dictadura militar, tan distante de una hipotética transición que, como concepto, perdía todo contenido.

Fue entonces cuando el tercer gobierno de la nueva democracia liberal, el liderado por Ricardo Lagos, tomó la iniciativa para maquillar la carta fundamental. Luego del acuerdo de todas las fuerzas políticas con representación en un congreso binominal, la reforma fue aprobada y publicada como Ley 20050 en 26 de agosto de 2005. Independiente de sus evidentes logros en pos de construir una plena democracia -como lo fueron la supresión de los senadores vitalicios e institucionales, la reforma al sistema de nombramiento de los miembros del Tribunal Constitucional ("TC") y la disminución del poder del Consejo de Seguridad Nacional-, el hecho que desde ese momento la carta tuviera la firma de Lagos, y no la de Pinochet, simbólicamente daba cuenta de una continuidad de la dictadura para sus dieciséis años siguientes, más que una transición hacia ninguna parte.

\section{Cultura}

Por lo señalado anteriormente, en vez de transición nos referiremos a esos años como la Continuación. Siendo esto continuación, no podemos omitir algunas características auspiciosas del desarrollo cultural para este tiempo y espacio. Sobre la base de la liberalización económica proyectada a niveles inusuales, la cultura en general tuvo algunas características significativas.

El fin de la represión sistemática generada desde un estado policial fue lo más relevante. Las instancias de apertura fueron reales: el toque de queda se acabó así como la censura previa, y se firmó una ley que -al menos en la forma- acaba con la detención por sospecha5, por mencionar dos hitos representativos. Ello condujo a una sensación de libertad que no se había vivido durante casi veinte años, aunque las circunstancias indicarían que aquello no era tan así.

Por otro lado, desde el segundo lustro de la década de 1980 se había constituido una escena subterránea donde espacios como el Garage de calle Matucana no 19 o el Trolley de San Martín no 841 bien daban cuenta de un underground donde convivían manifestaciones culturales de protesta contra la dictadura, con expresiones artísticas de vanguardia y música hardcore y punk. Esta escena conformó un ámbito de desarrollo cultural donde lo transgresor se relacionaba con lo hedonista y la vanguardia con lo subterráneo, que fue uno de los

${ }^{5}$ Ley 19567, promulgada el 22 de junio de 1998. Disponible en web: https://www.leychile.cl/Navegar?idNorma=120617\&buscar=19567. [Consulta: 10 de octubre de 2019] 
sellos de la cultura durante nuestro período. Las fiestas Spandex ${ }^{6}$, las actuaciones de Las Cleopatras 7 y las performances de Vicente Ruiz fueron una muestra de aquello, aunque posiblemente su máxima expresión fue el colectivo Las Yeguas del Apocalipsis, cuyas acciones de arte se inauguraron en 1987 y se proyectarían hasta 1993. Pedro Lemebel (1952-2015) y Francisco Casas (1959), sus integrantes, pasaron a transformarse en íconos de la cultura en Continuación.

Lemebel fue también emblema de otra característica de esta cultura: la aparición de nuevas contradicciones. Parte importante de la apuesta de las Yeguas..., y constituyente basal de la obra individual de Lemebel fue la reivindicación de las diversidades sexuales. El mundo homosexual empezó a evidenciarse en una sociedad tan conservadora como la chilena, desde las performance y acciones de arte de dragqueens, transformistas y travestis, quienes salían de la oscuridad para con orgullo ocupar un espacio social hasta el momento, negado. La convocatoria a la primera marcha por la diversidad sexual, en 1999, daba cuenta de ello.

Pero no sólo se visibilizó la diversidad sexual; problemáticas como la causa mapuche y la defensa del medio ambiente fueron también muestras de esta irrupción de nuevas contradicciones. Dentro de lo primero, la participación como candidato presidencial en la elección de 2005 del líder mapuche del Consejo de Todas las Tierras -fundado en 1989- Aucán Huilcamán, es un buen ejemplo8. Sobre la advertencia pública de la depredación de la naturaleza, bien lo representa la organización de ecologistas en torno a Los Verdes, colectivo liderado por Andrés Koryzma, emanado del Partido Humanista, fundado en 1987 y con presencia hasta el 2001; y el Movimiento Ecologista, existente por poco tiempo (1993-1994) pero sumamente influyente al perfilar a su líder Manfred Max Neef como candidato en la elección presidencial de 1993.

Sobre el ejercicio artístico cultural, es decir, la experiencia social de la cultura desde su variable artística, cuatro pueden ser los principales atributos: individualización, tecnologización, audiovisualización e internacionalización. Lo primero es casi connatural al modelo; la implementación de un capitalismo clásico y la jibarización brutal del Estado lleva a privilegiar al ser individual por sobre al ente colectivo y social, transformándose la competencia en el ethos y la "innovación y emprendimiento" en la aspiración máxima y plena de la gestión en sociedad.

\footnotetext{
6 Uno de sus gestores, Daniel Palma, comentaría al respecto años después: "Somos hijos de esa trampa que fue la transición". The Clinic, 22 de julio de 2015. Disponible en web: https://www.theclinic.cl/2015/07/22/habla-el-creador-de-las-miticas-fiestas-spandex-somos-hijosde-esta-trampa-que-fue-la-transicion/ [Consulta: 13 de marzo de 2018]

7 Las Cleopatras fue una agrupación artística multimedial integrada por Cecilia Aguayo, Jacqueline Fresard, Tahía Gómez y Patricia Rivadeneira.

8 Huelga referirse al establecimiento de la Corporación Nacional de Desarrollo Indígena, creada en 1993, y la arremetida de acciones de recuperación de tierra de parte de comunidades mapuches, que empezó con 16 predios tomados en 1992.
} 
Hobsbawm ya escribía hacia 1994: "La revolución cultural de fines del siglo XX debe, pues, entenderse como el triunfo del individuo sobre la sociedad o, mejor, como la ruptura de los hilos que hasta entonces había imbricado a los individuos en el tejido social" (Hobsbawm, 1998: 336).

Las personas naturalizaban la experiencia artístico cultural de modo individual. Dejó de ser circunstancial para hacerse normal el uso de audífonos para escuchar música, o el disfrute de una película en la doméstica y privada pantalla del computador en vez de la colectiva experiencia desde el ecran. Pero ello era también porque la tecnología lo permitía. Efectivamente, el frenético desarrollo tecnológico, especialmente de lo digital, parecía privilegiar el medio por sobre el mensaje. "La tecnología no sólo hizo que el arte fuese omnipresente, sino que transformó su percepción", afirmaba el mismo Hobsbawm (1998: 497).

$Y$ en esa tecnología, en términos culturales, dominante era el mensaje audiovisual. La pantalla, primero del televisor (colorizado y ultramasificado en Chile desde fines de la década de 1970), luego del ordenador y finalmente del teléfono portátil, se transformó en el principal emisor de productos culturales, la mayor parte con sonido e imagen en movimiento. El producto digital, asimismo, se fue conformando en la aspiración no sólo de la socialización de la creación artística, sino más bien en el soporte por excelencia de la misma.

Finalmente, como signo de nuestros tiempos y elemento imprescindible de mencionar es la internacionalización. Ésta en nuestra historia se empezó a manifestar de modo más vertical que horizontal; más que el intercambio democrático y en similares condiciones de comunicación, la incorporación cultural de tendencias exógenas y la transmisión hacia el extranjero de lo mismo se dio en condiciones de diferencia, las que se hicieron presentes al menos también en la última década del siglo XX. El retorno de artistas desde el exilio significó la importación de sensibilidades estéticas y creativas que difícilmente hubieran podido desarrollarse desde un ejercicio intramuros, enriqueciendo el acontecer local pero también incorporando nuestras prácticas a un mundo donde lo occidental daba paulatino paso a lo mundial o global, desde la periferia hacia el centro, para luego nuevamente hacia la periferia, hasta lo global.

Pero no sólo en términos superestructurales; la internacionalización intervino también todo el ámbito estructural, lo que se hizo evidente en la participación activa en el mercado musical chileno de transnacionales discográficas que condicionarían en parte importante el desarrollo de la música popular chilena.

\section{Música popular. Generalidades}

Hay un correlato entre estas características generales de la cultura en Continuación y la música popular del mismo tiempo. Desde esa perspectiva, lo 
sistémico fue por cierto preponderante. La continuación y maduración del ultraliberalismo económico llevó a que la individualización también afectara el desarrollo musical. Muchas veces la producción ahora dependía de la obtención de fondos concursables ${ }^{9}$, en que la competencia entre pares conspiraba con la necesidad de construcción de proyectos colectivos con función social. Era la lógica del modelo que pretendía reproducirse en el quehacer artístico.

Por otro lado, el fin de la dictadura permitió el retorno de numerosos artistas cargados de nuevas obras, aprendizajes y experiencias que enriquecerían la escena musical chilena, otorgándoles principalmente una internacionalización, una apertura hacia el mundo desde su reputación ganada en lejanos confines y desde la asimilación de nuevas sonoridades incorporadas en esas mismas latitudes.

Pero esa apertura no fue sólo hacia el mundo, sino también al interior de nuestra sociedad nacional. El fin de los estados de excepción permitió que la música ocupara las calles y la noche como no lo había hecho durante más de una década. Fiestas y raves desde los espacios privados y carnavales y pasacalles desde el espacio público, parecían dar cuenta del éxtasis de un Chile que recuperaba la libertad y la democracia. En este último sentido, bien vale la pena advertir la relevancia de un evento artístico que se transformaría en consular.

En 1987, una generación de actores, apoyados por jóvenes y talentosos músicos y respaldados por el autor de los versos que inspirarían el argumento, empezaron a trabajar en la teatralización de las décimas de Roberto Parra -"El Tío Roberto", hermano de Violeta- referidas a las memorias de sus aventuras en un lupanar de San Antonio regentado por "La negra Ester". Sería ésta el título de la obra estrenada el 9 de diciembre de 1988 en la plazuela O'Higgins de Puente Alto, que a fines de año trasladaría sus funciones al cerro Santa Lucía, del centro de Santiago, y que a los pocos meses se transformaría en la obra de teatro más vista de la segunda mitad del siglo XX chileno. Junto a ella, la Regia Orquesta acompañante consolidaría la fusión descongestionada entre la música popular, el jazz y el rock chilenos, a través de músicos integrantes como Álvaro Henríquez o Cuti Aste; y además, el carácter carnavalesco, callejero y circense de la reconocida obra, de alguna forma se transformó en la acreditación de excelencia que necesitaba el carnaval para desarrollarse libremente en las calles de Santiago.

Desde una perspectiva más institucional, la música popular en este tiempo tuvo dos particularidades que vale la pena exponer. Primero, su incipiente academización. No fue un acontecimiento raro si consideramos que pasó algo parecido con las vanguardias artísticas. La creación de escuelas de rigor académico cuyo tópico no era la música de arte sino la masiva, mediatizada y moderna,

9 En 1992 se creó el Fondo de Cultura FONDEC, que luego se denominaría Fondos Nacional de Desarrollo Cultural y de las Artes FONDART. 
permitió la consagración de la música popular como objeto digno de atención por los estudios superiores. El aporte del musicólogo Juan Pablo González en el Instituto de Música de la Pontificia Universidad Católica de Chile y en la formación hacia el año 2000 del Programa de Estudios Histórico-Musicológicos en la misma institución, la formación de la Escuela de Música de la SCD, la Escuela de Música de la Universidad Arcis en 2006 y la fundación en 2007 del Instituto Profesional Projazz bien dan cuenta de ello.

Una segunda particularidad fue el intento de organicidad que se dio entre sus actores. Compositores, arregladores, intérpretes y todos los trabajadores vinculados a la experiencia musical gestionaron distintas instancias de organización e institucionalización, algunas de las cuales tuvieron auspiciosos frutos y otros decepcionantes desenlaces. Dentro de los primeros, la Sociedad Chilena del Derecho de Autor (SCD), que se había establecido en 1987, se constituyó como entidad autónoma en 1992 y creó en 1998 la Sociedad Chilena de Intérpretes. Hasta hoy es el principal referente orgánico de la música popular chilena. Dentro de los segundos, la formación de la Asociación de Trabajadores del Rock, con una primera directiva constituida en diciembre de $19911^{10}$ y legalmente establecida como Asociación Gremial desde enero de 1992, fue una notable intento por perfilar al artista musical desde una consciencia de trabajador sindicalizado, mas, desgastes y desencuentros implicaron la disolución de la instancia hacia 1994. Le sucedería el proyecto de Escuelas de Rock, que al poco andar pasaría a depender de la burocracia estatal.

Un penúltimo aspecto a mencionar, relacionado con la tecnologización antes analizada, es la diversificación del escenario musical. La industria musical se ampliaba a medios, soportes y plataformas que ofrecían numerosas posibilidades de producción y difusión. Dentro de esto, lo vinculado al desarrollo computacional y el lenguaje digital es un tema tan complejo y contundente que no somos capaces de sintetizar en estas líneas, valga su alusión. En cambio, sí podemos referirnos a la radiodifusión. La multiplicación de las radios de Frecuencia Modulada fue notoria y la aparición de la radio Rock \& Pop, emblemática. La emisora empezó sus transmisiones en 1992 y marcó simbólicamente la irrupción en Chile de un proyecto mediático cuyo contenido se sostenía en la música popular chilena. Una revista y un canal de televisión serían, luego, parte del mismo proyecto.

Efectivamente, la televisión fue otra variable. La privatización de los mass media, evidenciada en el Decreto 71 publicado en noviembre de 1989, que permitía

\footnotetext{
10 La directiva estuvo constituida por: Presidente Claudio Narea, Vicepresidente Andrés Godoy, Claudio Gutiérrez como Secretario Ejecutivo, Max Siegel, del grupo Los Morton, como Tesorero, Juan Álvarez y Francisco Conejera como Directores. En: Gutiérrez, Claudio. "Historia de la Asociación de Trabajadores del Rock". Disponible en web: http://blog.canal.cl/2008/02/historia-de-la-asociacinde.html [Consulta: 24 de abril de 2020]
} 
a los entes privados entrar en la industria televisiva ${ }^{11}$, significó la salida al aire del primer canal privado por televisión abierta a través de la señal nueve, Megavisión, el 23 de octubre de 1990. Esto permitiría la aparición del primer canal segmentado de la historia: Rock \& Pop. Como su nombre lo indicaba, su objetivo fue proyectar la cultura musical desde la imagen en movimiento teletransmitida, proyecto que alcanzó a durar sólo tres años, entre 1995 y 1998. Diversos programas de música desde la televisión abierta completaban el panorama mediático: "Más música", hasta 1997; "Sábado taquilla", entre 1989 y 1994; y "Rojo. Fama contra fama", al aire desde 2002, son tres buenos ejemplos.

Esta televisión, referente de la reciente cultura audiovisualizada, diversificaba a plenitud su oferta desde la aparición de la televisión por cable en 1991. Canales internacionales como MTV, que desde 1993 tenía una señal exclusiva para Latinoamérica, o VH1, afirmaban una presencia de la música pop y rock desde la pantalla que aprovecharían inversiones nacionales para fundar canales como Vía X y Zona Latina, por el año 1991.

Fue esta misma dimensión televisiva la que puede representar un último aspecto dentro de este diagnóstico: la internacionalización, fase iniciática de la dominante globalización del tiempo presente. Chile y su música se vinculan al mundo desde el fin de la dictadura, no sólo por el fin de su aislamiento político, la llegada de influencias artísticas extranjeras por el regreso de los exiliados o la presencia de industrias musicales transnacionales. Es principalmente desde la internacionalización de los medios de comunicación que los mensajes sonoros comparten y conviven en espacios comunes con aquellos generados desde Europa, Estados Unidos e incluso África y Oriente12. Ya la industria musical tendía a la internacionalización desde el momento en que industrias musicales potentes como las norteamericanas -México y Estados Unidos- se constituían en imanes para artistas chilenos que buscaban proyección internacional. El cambio de residencia por los años sesenta o setenta del siglo veinte de artistas como Lucho gatica o Los Ángeles Negros se condecía con lo sucedido para nuestro período de análisis con agrupaciones como La Ley o Lucybell. Sin embargo, hay dos momentos ejemplares que dan cuenta de esta internacionalización en Continuación, y que sintetizan muchas de las características que hemos desarrollado hasta el momento.

El primero fue el 1 de octubre de 1993. Ese día, Music Televisión (MTV) inauguraba su señal para Latinoamérica. La transmisión fue iniciada con las palabras

\footnotetext{
11 Decreto 71. Disponible en web: https://www.leychile.cl/Navegar?idNorma=8685 [Consulta: 24 de abril de 2020]

12 Repitiendo la advertencia realizada hace algunas líneas, en este sentido Internet es factor imprescindible. Mas, nuestra debilidad en la comprensión de sus componentes e historia nos inhiben a plantearlo como contenido desarrollado.
} 
de un VJ chileno, Alfredo Levin13, quien presentaba el primer video transmitido por la señal. El tema era "We are Sudamerican Rockers", de Los Prisioneros, en video dirigido por Cristián Galaz. El mundo comunicacional consagraba a través de un medio el reconocimiento de una de las más importantes bandas de música popular chilena de todos los tiempos.

El segundo momento fue casi dos años después, el 14 de septiembre de 1995. Dicho día se presentó en el ciclo Unplugged de la misma cadena televisiva, el conjunto de rock chileno Los Tres. El que fuera uno de los conjuntos más populares del Chile de ese entonces, se presentaba en los estudios de la cadena televisiva interpretando sus mayores éxitos en versión acústica. Fue el final de su presentación lo que marcaría la diferencia. Para el cierre, optaron por interpretar jazz huachaca y cuecas choras, como homenaje al hace poco fallecido Tío Roberto Parra. Los ritmos propios de la música popular tradicional urbana chilena por primera vez eran difundidos masivamente, sorprendentemente desde un medio estadounidense. Parte importante del público chileno se amistaba con esas músicas desde la pantalla televisiva, recuperando la tradición local desde la transmisión global: la globalización se transformaba en "glocalización".

\section{Música popular. Movimientos y tendencias.}

En términos de movimientos musicales, descartando el mainstream del rock y el pop con figuras como Los Tres, La Ley, Javiera y Los Imposibles o Lucybell, podemos comprender el tiempo desde al menos cuatro tendencias, la última por sobre el resto.

Primero, la música electrónica sobre la base de la figura del Dj y el uso de sintetizadores y consolas de última generación. El discjockey -desde su acepción original de pincha-discos frente al micrófono de una radioemisora, a la usanza de clásicos como Raúl Matas, Ricardo García, Pablo Aguilera o Pirincho Cárcamo- en esta época pasa a asumir un rol protagonista como intérprete musical desde el reproductor sonoro sofisticado gracias a la tecnología, asumiendo un papel importante tanto en la música propiamente electrónica como en el rap.

Lo tecnológico, plasmado en mezcladores, consolas y sintetizadores, por un lado se estaba haciendo visible desde las fiestas subterráneas y alternativas en la discotheque Blondie (ex-cine Alessandri), inaugurada en 1993; las Fiestas Spandex, en los teatros Esmeralda, del barrio San Diego, y Carrera, del barrio Concha y Toro; y los eventos en el Centro Arte Alameda, ex cine arte Normandie, en el sector de Plaza Italia. Por otro, tenía ya un desarrollo germinal desde la contundente labor creativa

13 VJ es acrónimo de videojockey, "pincha videos", modernización del tradicional trabajador de la industria musical discjockey, "pincha discos". 
de agrupaciones como Electrodomésticos, Aparato Raro o Los Prisioneros, lo que en parte definió la consecución de proyectos artísticos que se plasmaron en interesantes colectivos musicales y fonogramas.

Por mencionar sólo tres de los referidos, uno de los grupos que generó más atención fue Los Mismos. Liderado por el ex Electrodomésticos Silvio Paredes y por donde pasaron artistas de la talla de Ernesto Medina, Gabriel Vigliensoni o Cuti Aste, la agrupación se formó en 1994 y dos años después editó su primer registro Trip-OMatic (Background), grabado en vivo en la disco Blondie. Hasta el año 2006 editaría cuatro discos: el mencionado más City tour (independiente, 1998), Pic-nic (Sello Azul, 2002) y Caspana (La Oreja, 2006)

Otra agrupación destacada fue Jardín Secreto, agrupación tecno-pop compuesta por los ex Prisioneros Miguel Tapia y Cecilia Aguayo. Afiatados en la electrónica desde el disco Corazones (EMI Odeon, 1990), el dúo editó su primer disco homónimo en formato compacto, producido por Juan Carlos Duque y editado por Warner en 1993. Lo sucedería sólo un segundo álbum antes de la disolución, autoeditado, llamado El sonido de existir, cuatro años después.

Sobre el tercer artista dentro de este ámbito, el siglo XXI testificaría la labor de una de las agrupaciones más identificadas con la música electrónica: Bitman \& Roban. El dúo compuesto por José Antonio Bravo y Christian Powditch marcaría el primer lustro del nuevo siglo, a la luz de tres halagados discos: Hurtos (Big Sur, 2000), Robar es natural (Big Sur, 2002) y Música para después del almuerzo (La Oreja, 2005).

Para terminar, y como afirma Fabio Salas respecto a la música electrónica, "se hace muy difícil de seguir su trayectoria en nuestro país en tanto música separándola de su función dancística" (Salas, 2003: 205); es difícil comprender este movimiento distanciándolo de su experiencia social colectiva. En este sentido debemos reconocer, como ya señalamos, los eventos en fiestas en la Blondie o el Centro Arte Alameda. Pero no sólo ello. Los amagos de destape chileno por la apertura en los gobiernos de la Continuación permitieron la realización de fiestas electrónicas públicas a la usanza de las raves europeas. Así, Love Parades al estilo berlinés fueron noticia al "festivalizar" Santiago desde espacios públicos como el Parque Forestal, el Parque Almagro o el Parque O'Higgins, conformando una escena cultural que bien representaba simbólicamente la sociedad chilena del período.

Una segunda tendencia está conformada por la canción de autor, que durante la década del noventa asumió el rótulo de "Novísima Canción". Con antecedentes evidentes en la Nueva Canción y el Canto Nuevo, la Novísima Canción se hizo cargo de una robusta tradición en Chile de la "cantautoría", para durante los años noventa y la primera década del siglo XXI producir obras que se situaban entre la música popular folclórica más contundente -manifestada en alusiones a Víctor Jara, Violeta 
Parra o Patricio Manns- y la renovación, a través de la incorporación de aires del jazz y el rock, con antecedentes en la obras de agrupaciones como Congreso o Los Jaivas. Asimismo, su desarrollo sorprendió al utilizar los eventos masivos mediáticos como plataforma de comunicación y desarrollo artístico, herencia de una dictadura cívico-militar que, al casi eliminar la producción discográfica nacional (Fuenzalida, 1985), perfiló a la televisión como medio casi exclusivo de socialización de la música popular. Así, no fue rara la exitosa participación de canciones y sus artistas vinculados a este movimiento en eventos como festivales de la canción o programas musicales televisivos, además de aquellos pubs -correlato para la Continuación de las precedentes peñas- o sencillas pero muy bien acondicionadas salas de concierto: La Casa en el Aire entre los primeros y la sala de la SCD entre las segundas.

Tan estructural como lo anterior fue que parte importante de la producción musical de sus cultores haya tenido el auspicio del Estado a través de los fondos concursables. Efectivamente, primero el Fondec y luego el Fondart se transformaron en fuentes de financiamiento imprescindible para la edición y distribución de fonogramas, propuestas que, o bien los sellos vinculados al mainstream desmerecían o no contemplaban por no ser parte de su política programática, o bien para los propios artistas era significativo editarlos de modo independiente de la estructura compuesta por los grandes consorcios.

Cuatro artistas podemos mencionar como ejemplares dentro de este ámbito. Alexis Venegas, el primero de ellos, se perfiló desde el año 1988, cuando ganó el Festival Víctor Jara con la canción "Posiblemente la verdad", para luego adquirir notoriedad masiva por participar en la competencia internacional del Festival de la Canción de Viña del Mar, representando a Chile con el tema "Deja la vida a volar". El mismo se transformó en el tema principal de su primer álbum, de igual nombre que la canción, editado por Fondart el año 1999. Otros dos discos editó durante el período de nuestro estudio: Cierto día... cierta noche (Machi, 2003) y Tus ojos (Machi, 2004). Fue con la canción que le dio el nombre a este último álbum que el artista, el mismo año, ganaría el mismo festival de la ciudad jardín, pero ahora en la competencia folclórica.

Tres mujeres completan esta muestra. Bajo la inspiración de maestras como Violeta Parra, Margot Loyola o Gabriela Pizarro, la Novísima Canción tuvo un destacado aporte desde el género femenino, con nuevas versiones de los clásicos de la canción popular e inspiradas creaciones donde la excelencia lírica y musical no estaban ausentes. Magdalena Matthey, una de ellas, irrumpía en la cultura masiva desde su canto de raíz tradicional, luego de consagrarse en 1995 como ganadora de la competencia folclórica del Festival de Viña del Mar, gracias a su canción "María Leonor Lucía". Esta instancia le permitió firmar contrato con el major EMI Odeon y publicar su primer disco, Latidos del alma, en 1997. Diferencias artísticas hicieron 
que la cantautora se independizara del sello y sus productores para tomar ella misma las riendas de su segunda obra, Del otro lado (Fondart, 1999). Pero fue con su tercer disco compacto cuando -en la humilde opinión del autor de estas líneasMatthey alcanzó la madurez en un fonograma de excelencia, donde los aires folclóricos se fusionaban con los sones contemporáneos en un disco que terminaría siendo exaltado por la crítica: Mañana será otro día (Machi, 2004).

Los elementos académicos se advierten más presentes en Francesca Ancarola, licenciada en música de la Universidad de Chile. Sus guiños con la música docta y el jazz le permitieron compartir experiencias creativas con Antonio Resetucci, Juan Antonio Sánchez o Federico Dannemann. Sin embargo, es la obra de Víctor Jara la que marcó en gran parte las composiciones de la artista durante la Continuación. Elocuente es, en ese sentido, que su primer disco se titulara Que el canto tiene sentido (autoedición, 1999), parafraseando "Manifiesto" de Víctor Jara, y su sexto álbum llevara por nombre Lonquén (Fondart, 2006), también en alusión a una composición de Jara. Ratificando una de las tendencias que habíamos advertido, de los seis discos de Ancarola, publicados entre 1999 y 2006, todos los editados en Chile fueron autoedición o financiado por Fondart. Sólo uno del total de seis no lo fue: Sons of the same sun (2003) fue editado en California, EE.UU., por el sello Petroglyph Records.

La tercera artista es Elizabeth Morris. Retornada del exilio desde la República Democrática Alemana y con estudios de música en la Universidad de Chile y en la Escuela de Artes de la Música Popular de la SCD, ha participado como invitada en numerosos discos. Fue a comienzos del siglo XXI cuando empezó a desarrollar su carrera como solista grabando su álbum debut, Hacia otro mar (Fondart, 2002). Cuatro años después ganaría también la competencia folclórica del Festival de la Canción de Viña del Mar con su composición "Canción de agua y viento".

La tercera tendencia significativa en el desarrollo de la música popular durante el período fue aquella que recuperaba lo afro. Durante el tiempo analizado, y sumamente relacionado con aquella irrupción de nuevas contradicciones que escribíamos en párrafos anteriores, en Chile se dio un reconocimiento de raíces africanas que pocas veces se habían considerado como parte constituyente de nuestra identidad. Si bien el reconocimiento legal al "pueblo tribal afrodescendiente chileno" fue recién en 201914, su influencia en la cultura popular ya se notaba en carnavales callejeros donde batucadas y candombes convivían con diabladas y morenadas. Mas, lo afro tuvo varios matices y diversas formas de manifestación desde la música que vale la pena reconocer.

14 La Ley 21151 "Otorga reconocimiento legal al pueblo afrodescendiente chileno". Publicada en 16 de abril de 2019. Disponible en web:

https://www.leychile.cl/Navegar?idNorma=1130641\&buscar=21151 [Consulta: 5 de septiembre de 2019] 
Primero, desde la fusión latinoamericana, ámbito en que la figura de Joe Vasconcellos fue gravitante. Desde su participación en el grupo Congreso, por los primeros años de la década de 1980, Vanconcellos aportó con sus aires afros y multiculturales que luego se plasmarían en su obra individual, iniciada con el álbum Esto es sólo una canción, grabada por Alerce en 1989. Es notable advertir que de los siete discos que ha sacado el artista como solista, seis los hace entre 1989 y 2005, transformándose posiblemente en el artista más emblemático y popular de la Continuación. Es también sumamente representativo, en términos simbólicos, su vínculo con el período, al ser su relación con los sellos ejemplo de la tendencia que hemos apuntado. Vasconcellos empieza grabando con un sello pequeño pero muy importante: Alerce; el éxito de su primera obra le permitió firmar contrato con un major, EMI Odeon, con el que grabó sus tres siguientes fonogramas: Verde cerca (1992), Toque (1995) y Transformación (1997); conflictos con la transnacional lo llevan a recuperar su independencia, para autoeditar sus siguientes dos registros, En paz (2003) y Banzai (2005, reeditado por Oveja Negra en 2006). La influencia y popularidad de Vasconcellos se acreditó con su disco Vivo, grabado desde dos conciertos realizados en el Teatro Providencia durante 1999. La frescura del sonido y la atmósfera del público hicieron que éste fuera el disco más vendido de su carrera y uno de los más populares del período de análisis.

Luego, el funk y el soul. Tres agrupaciones al respecto pueden considerarse representativas: Chancho en Piedra, primero, quienes desde impulsos adolescentes a comienzos de los años noventa consiguieron en 1995 grabar su primer registro para el sello Alerce, Peor es mascar lauchas, al que le sucederían cinco nuevos álbumes de estudio hasta 2005, los cuatro últimos grabados con el major Sony Music; Los Tetas, segundo, quienes nacieron desde el dúo Dr. Funkestein, formado en 1993 por Cristián Moraga y David Eidelstein, para luego como Los Tetas grabar desde 1995 cuatro discos hasta 2002 (grabarían un quinto en 2012), los dos primeros con EMI Odeon y los siguientes con Sony Music; y, finalmente, Mamma Soul, agrupación que, habiendo editado sólo un disco en el período ( $F e$, EMI Odeon, 2001), destacó en la escena por la excelencia de su sonido, la mezcla entre soul, reggae, blues y aires latinoamericanos, más la composición exclusivamente femenina de sus integrantes, atributo inusual para los conjuntos de aquel entonces.

Finalmente, dentro de este ámbito, fueron estos los tiempos de popularización definitiva del reggae. Si bien hubo experiencias anteriores más que significativas -Compañeros de Viaje y Los Prisioneros, por nombrar sólo dos conjuntos- fue en esta época cuando el imaginario rastafari se consolidó junto a su música jamaiquina, gracias principalmente a la irrupción y popularidad de Gondwana. El conjunto, oriundo de la población La Pincoya y con orígenes por el año 1987, alcanzó gran popularidad desde su primer registro el año 1997 (BMG), 
homónimo, y en parte gracias al carisma e imagen de su vocalista Quique Neira, quien se había incorporado un año antes al conjunto. Con esta agrupación grabaron tres discos: el mencionado más Alabanza (BMG, 2000) y Made in Jamaica (EMI Odeon, 2002). El año 2004 editaron un cuarto álbum, bajo el liderazgo del bajista y fundador Claudio Labbé y el primero sin su, hasta ese momento, emblemático vocalista.

"Podemos comprender el tiempo desde al menos cuatro tendencias, la última por sobre el resto", amenazábamos en párrafos anteriores. Esta última es el Rap.

La música chilena presentó elementos de rap desde fines de la década de 1980. Con antecedentes de cultura hip-hop hacia mediados de la década ochentera, cuando los primeros B-boys practicaban sus pasos en calle Bombero Ossa o en la explanada de calle Portugal, a un costado del entonces supermercado Unicoop, inspirados por las películas Beatstreet y Breaking, ambas exhibidas en cines en 1984; Los Prisioneros en su ya aludido tema "We are sudamerican rockers" (EMI Odeon, 1987), presentaban la técnica de los MC's 15 en la vocalización de la letra, estilo que se hacía evidente en la interpretación del tema "Corazones rojos", del disco Corazones (EMI Odeon, 1990), en los años 1987 y 1990, sucesivamente. Sin embargo, el género se perfiló de modo definitivo desde el conjunto De Kiruza. La aparición de su primer registro sonoro homónimo (autoedición, 1988) -que bien podríamos haber incorporado en la tendencia afrolatina descrita hace algunos párrafos-, significó la masificación dentro del ambiente musical de dos temas del género: "De Kiruza" y "Algo está pasando". Junto a ellos la banda Panteras Negras, oriundos de la población Huamachuco de la comuna de Renca, grababan en 1991, también bajo un sello independiente su disco debut Lejos del centro. Sobre todo con estos últimos, la realidad de los barrios marginales y la denuncia de sus precarias condiciones de vida se plasmaba ahora desde los sones de la cultura hip hop, ya no desde los aires musicales de raíz folclórica, como había ocurrido con la protesta musical durante la segunda mitad del siglo XX. Dos años después firmarían contrato con el sello Alerce, con el cual sacarían otros tres fonogramas: Reyes de la jungla (1993), Atacando calles (1996) y La ruleta (1997). Junto a ellos y por el mismo tiempo, Jimmy Fernández y Rodrigo Méndez formaban Latin Posse, agrupación que, con el reemplazo de Méndez por Hernán del Canto, grabarían su primer disco Pozzeídos por la ilusión, esta vez bajo el nombre de La Pozze Latina (Alerce, 1993).

La aparición del rap en Chile fue notoria y gravitante en la década, y los sellos transnacionales acusarían recibo del fenómeno. EMI Odeon en 1997 editaba el disco Ser humano, álbum debut de la banda Tiro de Gracia. Temas como "El juego

\footnotetext{
15 El concepto MC viene del anglo "master of ceremonias", categoría que adquiere el rapero vocalista, quien, junto al encargado de la consola de sonido o DJ, conforman las agrupaciones de rap más frecuentes.
} 
verdadero" y "Viaje sin rumbo" alcanzaron niveles de difusión inusuales para el género en el ambiente musical chileno, vendiendo el disco en un año la notable cifra de sesenta mil copias ${ }^{16}$, transformándose en el disco que masificó el rap en Chile. A este le sucederían otros tres registros ${ }^{7}$, hasta que la banda se disolvió comienzos del siglo XXI. También en 1997 irrumpía Makiza, con la destacada participación de Ana Tijoux, quien el poco andar emprendería una destacada carrera como solista. Antes, dejarían dos registros en la década: Vida salvaje (autoedición, 1998) y Aerolíneas Makiza (Sony Music, 1999).

El primer lustro del siglo XXI afirmaría el género en la escena musical chilena. En 2001 debutaba con Destino invisible (LDRO Producciones) la agrupación femenina Corrosivas; con TTBA (Top Ten Babylon Artistas) (Big Sur) el dúo DJ Raff y Solo Di Medina; con Primer Acto (independiente) los Trovadores Tales; y con Subdemo (Dilema Industria) la agrupación FDA, Fe por un Destino Anunciado. Al año siguiente aparecía el disco Hermanos Brothers (Mutante discos) del grupo homónimo, y Hernán del Canto encabezaba el proyecto que daría a luz el compilado doble Joyas del barrio. Poco tiempo después, en 2005, Makiza lanzaría su último álbum Casino Royal (La Oreja).

Ese mismo año 2005, la Constitución de 1980 dejaba de llevar la firma del general Augusto Pinochet y de su gabinete, para tener de ahora y en adelante la rúbrica del presidente Ricardo Lagos y sus ministros.

\section{Palabras finales. Guerra en las calles}

El rap constituye la mayor representación simbólica del período de Continuación. Tanto en su propuesta artística como en su experiencia social confluyen de modo más evidente los componentes de la cultura de este tiempo.

La internacionalización es su sino: el género proviene de la internacionalización de los mass media, mensajes que desde mediados de la década del ochenta constituyen las primeras manifestaciones de la cultura hip hop. Es más, muchos de los integrantes de bandas señeras provenían del extranjero18. Siendo inicialmente una cultura importada, al poco andar adquiere identidad nacional desde el idioma y los contenidos de su lírica. Con el tiempo, las pistas incluidas en sus sampler incorporarían música popular chilena, y el MC usaría el género para

16 "Tiro de Gracia a 20 años de su disco Ser Humano". La Tercera/Culto, 4 de agosto de 2017. En: https://www.latercera.com/culto/2017/08/04/tiro-gracia-a-20-anos-disco-humano-cuando-losacamos-nos-pusieron-ene-restricciones-viaje-sin-rumbo-lo-censuraron/ [Revisado en 20 de marzo de 2020]

17 Decisión, EMI Odeon, 1999; Retorno de misericordia, EMI Odeon, 2001; y Patrón del vicio. EMI Odeon, 2003.

18 De Makiza, Anita Tijoux provenía de Francia, Seo2 de Suiza y Cenzi de Canadá; de La Pozze Latina, Jimmy Fernández venía de Italia y Hernán del Canto, de República Democrática Alemana. 
rescatar, incluso, la vigencia de la lengua de nuestros pueblos originarios ${ }^{19}$, funcionando también la internacionalización como recuperación de tradiciones e identidades locales.

El rap es también tecnologización. En su interpretación, el instrumento musical dejó su lugar a la máquina reproductora de sonido, fuera ésta tornamesa, mezcladora o consola; lo que antes era un mero reproductor se transformó en instrumento generador de sonidos desde aquellos preestablecidos, pregrabados. El hombre común podía hacer música, pues se transformaba en instrumento aquel aparato que históricamente le había servido para formar parte de la experiencia musical en la sociedad: el reproductor musical.

El rap fue también audiovisualización. El videoclip de la canción "Con el color de mi aliento", de la Pozze Latina, sería el primer video de Hip Hop hecho en Latinoamérica emitido por MTV Latino en 1994. Si a ello le sumamos que "We are sudamerican rockers" fuera el primer videoclip emitido por la señal un año antes, tenemos al rap como género significativo en la música como experiencia audiovisual para el período. Sin embargo, también es tensión y conflicto.

Aquella individualización que se proponía como parte constituyente de la experiencia musical y cultural de la época, se tensiona cuando el rap aparece como el rescate y perfilamiento de las realidades locales, donde el sentir comunitario y la reivindicación social entran en conflicto con el modo de vida burgués imperante. Y esto genera tensión, provoca y, como buena acción, genera reacción, llevando a cuestionar nuevamente la cómodamente llamada Transición, en su posiblemente mayor atributo: su apertura.

$\mathrm{Al}$ respecto, un hito parece bien representar lo escrito. El 16 de diciembre de 1995 se realizaba un concierto en el Estadio Nacional que contó con la participación de una serie de agrupaciones que formaban parte del proyecto Nuevo Rock Chileno, del sello Alerce en colaboración con Sony Music. En el evento desfilaron por el escenario conjuntos como Los Miserables, Chancho en Piedra, La Pozze Latina y Panteras Negras. El evento fue transmitido en directo por la televisión abierta, cuando subió al escenario la agrupación liderada por Lalo Meneses. Su interpretación de "Guerra en las calles" fue uno de los momentos más frenéticos y de complicidad entre artistas y público, más aún cuando todos en coro gritaban al son de la letra del tema, "pacos culia'os". La ofensa fue escuchada por todo Chile, y significó el levantamiento de una querella por injurias presentada por Carabineros contra el conjunto Panteras Negras. En junio de 1996 se dictó una orden de aprehensión contra Meneses, quien tuvo que sumergirse en la clandestinidad hasta

\footnotetext{
19 Un destacado rapero del tiempo presente es Luanko, MC y profesor de historia de origen mapuche, quien interpreta rap en mapudungun. Se sugiere escuchar el tema "Wiñoy Tañi Kewvn" ("Volvió mi lengua").
} 
acogerse un recurso de amparo para revertir la situación. La Transición mostraba su real cara: esta era, a la luz de la experiencia social de la música, la continuación del sistema fundado bajo la dictadura.

\section{Bibliografía}

Aylwin, P. (1990): Discurso en el Estadio Nacional del 12 de marzo de 1990, en Archivo Presidencial. Disponible en web: https://www.gob.cl/noticias/el-discursocon-que-patricio-aylwin-reinauguro-la-democracia-1/ [Consulta: 5 de julio de 2019]

Burke, P. (2010): Hibridismo cultural. Madrid, Akal.

Claude, M. (c1997): Una vez más la miseria: ¿es Chile un país sustentable? Santiago de Chile, LOM.

Chartier, R. (1992): El mundo como representación. Barcelona, Gedisa.

Chile. Corporación Nacional de Reparación y Reconciliación y Comisión Nacional de Verdad y Reconciliación (1991): Informe de la Comisión Nacional de Verdad y Reconciliación. Santiago, La corporación.

Fuenzalida, V. (1985): La industria fonográfica chilena. Santiago, CENECA.

Gárate, M. (2014): La revolución capitalista de Chile (1973-2003). Santiago, Universidad Alberto Hurtado.

Geertz, C. (1973): La interpretación de las culturas. Barcelona, Gedisa.

Gutiérrez, C. (2008): Historia de la Asociación de Trabajadores del Rock. Disponible en web: http://blog.canal.cl/2008/02/historia-de-la-asociacin-de.html [Consulta: 24 de abril de 2020]

Hosbawm, E. (1998): Historia del siglo XX. Buenos Aires, Crítica.

Jocelyn-Holt, A. (1998): El Chile perplejo. Del avanzar sin transar al transar sin parar. Santiago, Plantea.

Moulian, T. (1997): Chile actual. Anatomía de un mito. Santiago, Lom.

Rolle, C. y J. P. González (2005): Historia Social de la Música Popular en Chile, 18901950. Santiago, Universidad Católica de Chile. 
Salas, F. (2003): La primavera terrestre. Cartografía del Rock Chileno y la Nueva Canción Chilena. Santiago, Cuarto Propio.

\section{Discografía}

Alexis Venegas (1999): Deja la vida a volar. Fondart. Disco Compacto.

Alexis Venegas (2003): Cierto día... cierta noche. Machi. Disco Compacto.

Alexis Venegas (2004): Tus ojos. Machi. Disco Compacto.

Bitman \& Roban (2000): Hurtos. Big Sur. Disco Compacto.

Bitman \& Roban (2002): Robar es natural. Big Sur. Disco Compacto.

Bitman \& Roban (2005): Música para después del almuerzo. La Oreja. Disco Compacto.

Chancho en Piedra (1995): Peor es mascar lauchas. Alerce. Disco compacto.

Corrosivas (2001): Destino invisible, LDRO Producciones. Disco compacto.

De Kiruza (1988): De Kiruza. Independiente.

DJ Raff y Solo Di Medina (2001): TTBA (Top Ten Babylon Artistas). Big Sur. Disco compacto.

Elizabeth Morris (2002): Hacia otro mar. Fondart. Disco Compacto.

FDA, Fe por un Destino Anunciado (2001): Subdemo. Dilema Industria. Disco compacto.

Francesca Ancarola (1999): Que el canto tiene sentido. Autoedición. Disco Compacto.

Francesca Ancarola (2006): Lonquén. Fondart. Disco Compacto.

Francesca Ancarola (2003): Sons of the same sun. Petroglyph Records. Disco Compacto.

Gondwana (1997): Gondwana. BMG. Disco Compacto. 
Gondwana (2000): Alabanza. BMG. Disco Compacto.

Gondwana (2002): Made in Jamaica. EMI Odeon. Disco Compacto.

Hermanos Brothers (2002): Hermanos Brothers. Mutante discos. Disco compacto.

Jardín Secreto (1993): Jardín Secreto. Warner. Disco Compacto.

Jardín Secreto (1997): El sonido de existir. Autoedición. Disco Compacto.

Joe Vasconcellos (1989): Esto es sólo una canción. Alerce. Disco Compacto.

Joe Vasconcellos (1992): Verde cerca. EMI Odeon. Disco Compacto.

Joe Vasconcellos (1995): Toque. EMI Odeon. Disco Compacto.

Joe Vasconcellos (1997): Transformación. EMI Odeon. Disco Compacto.

Joe Vasconcellos (1999): Vivo. EMI Odeon. Disco Compacto.

Joe Vasconcellos (2003): En paz. Autoedición. Disco Compacto.

Joe Vasconcellos (2005): Banzai. Autoedición. Disco Compacto.

La Pozze Latina (1993): Pozzeídos por la ilusión. Alerce. Casete.

La Pozze Latina (1993): Pozzeídos por la ilusión. Alerce. Disco Compacto.

Los Mismos (1994): Trip-O-Matic. Background. Disco Compacto.

Los Mismos (1998): City tour. Autoedición. Disco Compacto.

Los Mismos (2002): Pic-nic. Sello Azul. Disco Compacto.

Los Mismos (2006): Caspana. La Oreja. Disco Compacto.

Los Prisioneros (1987): La cultura de la basura. EMI Odeon. Disco Compacto.

Los Prisioneros (1990): Corazones. EMI Odeon. Disco Compacto.

Magdalena Matthey (1997): Latidos del alma. EMI Odeon. Disco Compacto. 
Magdalena Matthey (1999): Del otro lado. Fondart. Disco Compacto.

Magdalena Matthey (2004): Mañana será otro día. Machi. Disco Compacto.

Makiza (1998): Vida salvaje. Autoedición. Disco compacto.

Makiza (1999): Aerolíneas Makiza. Sony Music. Disco compacto.

Makiza (2005): Casino Royal. La Oreja. Disco compacto.

Mamma Soul (2001): Fe. EMI Odeon. Disco compacto.

Panteras Negras (1990): Lejos del centro. Autoedición. Casete.

Panteras Negras (1993): Reyes de la jungla. Alerce. Disco Compacto.

Panteras Negras (1996): Atacando calles. Alerce. Disco Compacto.

Panteras Negras (1997): La ruleta. Alerce. Disco Compacto.

Tiro de Gracia (1997): Ser humano. EMI Odeon. Disco compacto.

Trovadores Tales (2001): Primer Acto. Autoedición. Disco compacto.

Varios artistas (2002): Joyas del barrio. Autoedición. Disco compacto.

Fecha de recepción: 14 de abril de 2020

Fecha de aceptación: 17 de junio de 2020 